\title{
Utilization Of The Building-Block Approach In Structural Mechanics Research
}

\author{
Marshall Rouse, ${ }^{*}$ Dawn C. Jegley ${ }^{\dagger}$ David M. McGowan, ${ }^{*}$ Harold G. Bush ${ }^{\dagger}$ \\ NASA Langley Research Center Hampton, VA 23681 \\ and \\ W. Allen Waters ${ }^{\S}$ \\ Lockheed Martin Corp. Hampton, VA 23681
}

\begin{abstract}
In the last 20 years NASA has worked in collaboration with industry to develop enabling technologies needed to make aircraft safer and more affordable, extend their lifetime, improve their reliability, better understand their behavior, and reduce their weight. To support these efforts, research programs starting with ideas and culminating in full-scale structural testing were conducted at the NASA Langley Research Center. Each program contained development efforts that (a) started with selecting the material system and manufacturing approach; (b) moved on to experimentation and analysis of small samples to characterize the system and quantify behavior in the presence of defects like damage and imperfections; (c) progressed on to examining larger structures to examine buckling behavior, combined loadings, and built-up structures; and (d) finally moved to complicated subcomponents and full-scale components. Each step along the way was supported by detailed analysis, including tool development, to prove that the behavior of these structures was well-understood and predictable. This approach for developing technology became known as the "building-block" approach. In the Advanced Composites Technology Program and the High Speed Research Program the building-block approach was used to develop a true understanding of the response of the structures involved through experimentation and analysis. The philosophy that if the structural response couldn't be accurately predicted, it wasn't really understood, was critical to the progression of these programs. To this end, analytical techniques including closed-form and finite elements were employed and experimentation used to verify assumptions at each step along the way. This paper presents a discussion of the utilization of the building-block approach described previously in structural mechanics research and development programs at NASA Langley Research Center. Specific examples that illustrate the use of this approach are included from recent research and development programs for both subsonic and supersonic transports.
\end{abstract}

\section{Introduction}

In the last 20 years NASA has worked in collaboration with industry to develop enabling technologies needed to make aircraft safer and more affordable, extend their lifetime, improve their reliability, better understand their behavior, and reduce their weight. To support these efforts, research programs starting with ideas and culminating in full-scale structural testing were conducted at the NASA Langley Research Center. Each program contained development efforts that (a) started with selecting the material system and manufacturing approach; (b) moved on to experimentation and analysis of small samples to characterize the system and quantify behavior in the presence of defects like damage and imperfections; (c) progressed on to examining larger structures to examine buckling behavior, combined loadings, and built-up structures; and (d) finally moved to complicated subcomponents and full scale components. Each step along the way was supported by detailed analysis, including tool development, to prove that the behavior of these structures was well-understood and predictable. This approach for developing technology became known 
as the "building-block" approach and was used successfully in programs such as the Advanced Composites Technology Program (ACT) ${ }^{1-38}$ and the High Speed Research Program (HSR). ${ }^{39-43}$ Analysis techniques including closed-form and finite elements were employed. The intent was to always verify that the analysis and experimental data agreed because otherwise the behavior of the structure was not adequately understood.

In the 1980's Jim Starnes and others at NASA Langley saw the need for a major initiative to promote the use of light-weight composites on commercial transport aircraft. At the time, Langley's current programs were winding down and many issues involving the use of composites were yet to be resolved. Many discussions with industry and other government agencies resulted in the understanding that technical, cost, certification and manufacturing roadblocks all existed and must be overcome before any manufacturer would consider relying on composite primary structures for carrying passengers. The airlines also demanded that maintenance, safety, and cost issues be addressed before they would consider buying transports with composite primary structures. With these thoughts in mind, the Advanced Composites Technology (ACT) program was born. Jim led much of the initial work in organizing the program and implementing the program. The defined goal was to reduce the structural weight of a commercial transport aircraft by 30 to $50 \%$ while also reducing manufacturing costs by 20 to $25 \%$ and ensuring that the resulting structures behaved in a predictable manner, would meet FAA requirements for certification including the area of damage tolerance, and be repairable in a way that the airlines would find acceptable.

In 1989 fifteen contracts were awarded in Phase A of the program. ${ }^{3}$ Phase A was defined to be "technology innovation" where work in the areas of manufacturing techniques such as resin transfer molding, fiber placement and stitching technology were developed. Contracts were awarded to industry (Boeing Commercial Airplanes, Hercules, Lockheed Aeronautical Systems, Grumman, Rockwell International, BASF, Dow Chemical, McDonnell Douglas, Sikorsky, and Northrop) and universities (Stanford, University of Utah, University of Delaware and University of California-Davis). Phase A represents the first part of the building-block approach - initial investigations and characterizations. Phase B was considered "technology development" and represented the next step in both size and complexity of the structures. The program became more narrowly focused and by Phase C, "technology verification," ACT was focused on two prime contractors and two concepts. Each step was necessary for the following step to be successful. The results of these efforts are described in the following sections. Those original contracts helped develop the basic technology and understanding of material behavior and structural response. The building-block philosophy was critical to the success of this program.

In the mid 1990's, feasibility studies indicated that a High Speed Civil Transport (HSCT) with the capability to fly between Mach 2.0 and 2.5, with a capacity of 200 to 250 passengers and a range of 5,000 nautical miles might be economically feasible. These studies indicated that to be economically viable, the HSCT would have to provide a return on investment that was competitive with subsonic transport aircraft. Advancements in the current state of technologies were shown to be necessary to meet the manufacturing, maintenance, and operational cost requirement for a HSCT aircraft. In 1994, NASA initiated the High Speed Research (HSR) program to address these challenges. The goal of the HSR program was to develop the technologies needed to build a commercial transport aircraft capable of flying at Mach 2.4 for 5000 nautical miles at an altitude of $60,000 \mathrm{ft}$. The target vehicle was to be capable of carrying 300 passengers from California to the Pacific Rim in half the time and at only 1.2 times the cost of conventional subsonic vehicles. The vehicle weight goal was a 30\% reduction as compared to the Concorde supersonic transport.

In 1994, Phase I of the HSR program, trade studies were conducted to develop a configuration for a vehicle to meet the market requirements. In 1995, Phase II was initiated to develop the technology necessary for a HSCT vehicle. One area of technology development that was pursued was Material and Structures Technology Development. The Material and Structures Technology Development was further divided into elements or tasks which consisted of: Metallic Materials; Composite Materials; Materials Durability; Wing Structures; Fuselage Structures; Aeroelasticity; Acoustics; and Design Integration Trade Studies. These tasks were integrate together to develop the material processes, structural concepts and airplane configuration that met the design criteria and environmental constraints. This paper concentrates on aspects of the impact of building-block tests on the development of Wing and Fuselage Structures technology. 


\section{Material Characterization}

The first step in applying the building-block approach to the development of composite structure is to be able to quantify the mechanical properties of the composite material being considered. Compression, tension, and shear stiffnesses and strengths must be determined. In addition, failure mechanisms and nonlinear material responses must be quantified. Some typical material characterization tests are described herein, although these tests are only meant to be representative of the many tests needed to fully understand and predict the behavior of specimens constructed from new material systems.

\section{A. IITRI}

A typical method used to determine the compressive property of polymer matrix composite material is the ITTRI test method. The ITTRI can be used to determine the compressive strength and stiffness of a polymer matrix material. The method is describe in Ref. 44. An IITRI specimen and typical results for

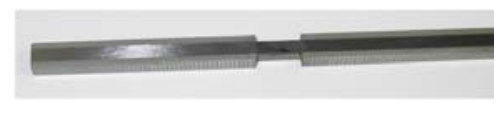

a) Photograph of typical specimen.

AS4/3502 graphite-epoxy unidirectional tape are shown in Fig. 1. A photograph of a ITTRI specimen is shown in Fig. 1a. Typical stress-strain results for a ITTRI test specimen that was tested to failure are presented in Fig. 1b. The applied stress is shown as a function of the surface strain results obtained from back-to-back strain gages oriented in the longitudinal

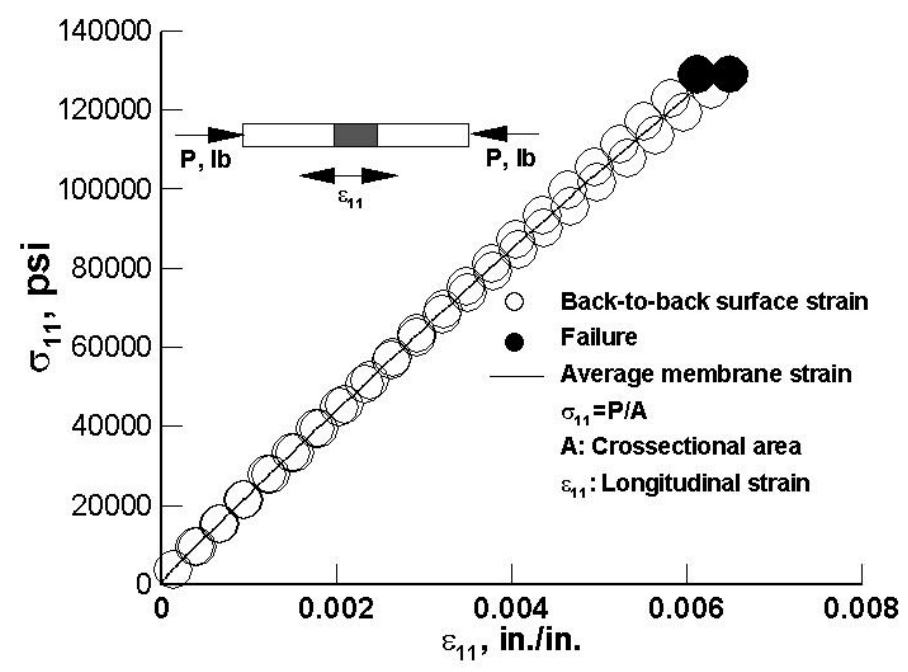

b) Typical strain results. direction and is represented by the open symbols. The filled symbols indicate failure of the specimen. The average membrane strain in the longitudinal direction is representation by the solid line.

\section{B. Isopescu}

The isopescu shear test is used to determine the shear strength and stiffness of a polymer matrix material. The method is described in Ref. 45. Typical results for

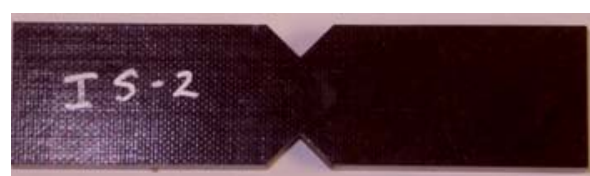

a) Photograph of typical specimen.

AS4/3502 graphite-epoxy uni-directional tape are shown in figure 2. A photograph of an isopescu specimen is shown in Fig. 2a. Typical stress-strain results for an isopescu test specimen that was tested to failure are

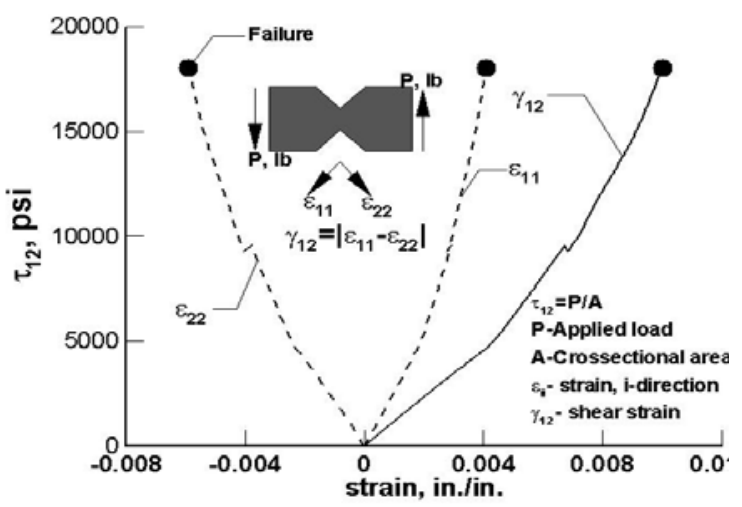

b) Typical strain gage results.

Figure 2. Summary of isopescu test. 
presented in Fig. 2b. The applied shear stress is shown as a function of the average memberane strain results taken from back-to-back strain gages oriented in the \pm 45 degrees to longitudinal axis and is represented by the dashed lines. The filled symbols indicates failure of the specimen. The average membrane shear strain in the longitudinal direction is represented by the solid line.

\section{Multi-Point Bending Tests}

Since layered composite structures have failure modes not seen in isotropic structures, certain types of testing became more critical than in a traditional aircraft development program. One such test was a multispan beam shear test. In the simplest case, this test is a 3-point bend test. However, a 3-point test does not apply the same stress state through the thickness of the structure as a 4- or 5-point test, and different failure mechanisms can be activated. ${ }^{46}$ The test set-up and typical results are shown in figure 3 for a 5-point-bend test. This set-up shows five rollers and a graphite-epoxy beam specimen in figure 3a. The failure mode of delaminations between plies and intraply cracks shown in Fig. $3 b$ are typical of a layered composite constructed from a brittle resin system. The white layers in the photograph are layers of an adhesive which was added to improve the damage tolerance capability of the specimen. Depending on the location of the layers, the number of adhesive layers and the overall stacking sequence, failure loads, and displacements at final failure could be increased. Such an adhesive layer had the effect of increasing the failure displacement, failure load, or both. Changes in load and

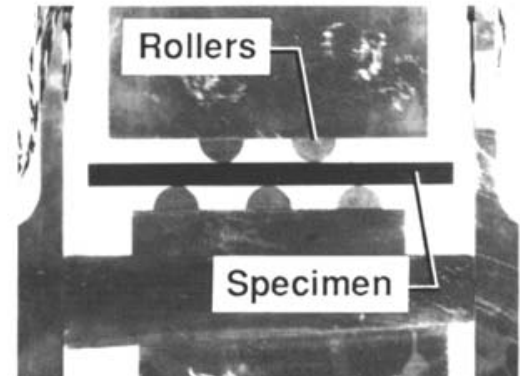

a) Photograph of test set-up. displacement as cracking progresses in a typical laminate are shown in Fig. 3c. Since brittle resin systems were common in the early 1980's and 1990's, these mechanisms were examined as they related to damage due to impact, external surface damage, stress concentrations and repair. This testing technique was valuable as an initial screening test in determining the damage tolerance of composite material systems - a necessary step in evaluating a material system's usefulness in aircraft structural applications. ${ }^{47}$

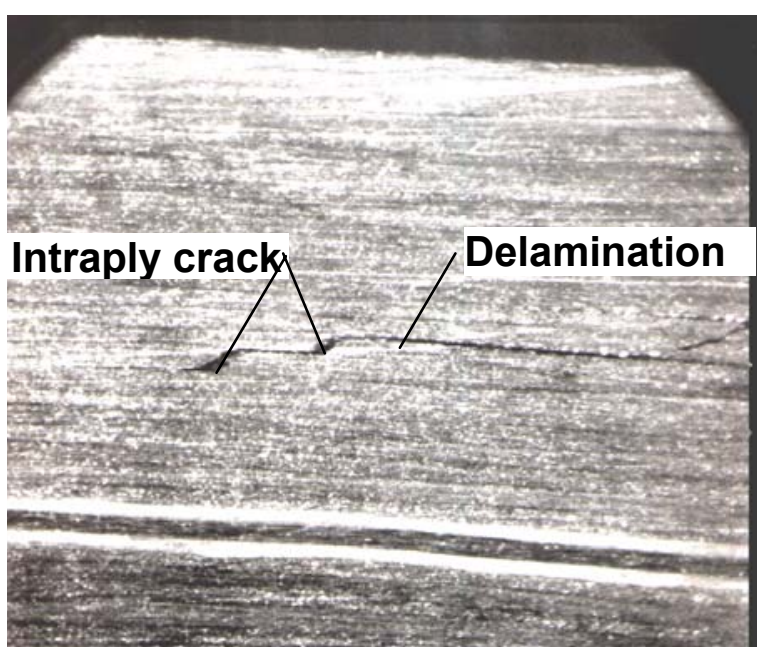

b) Cracks and delaminations.

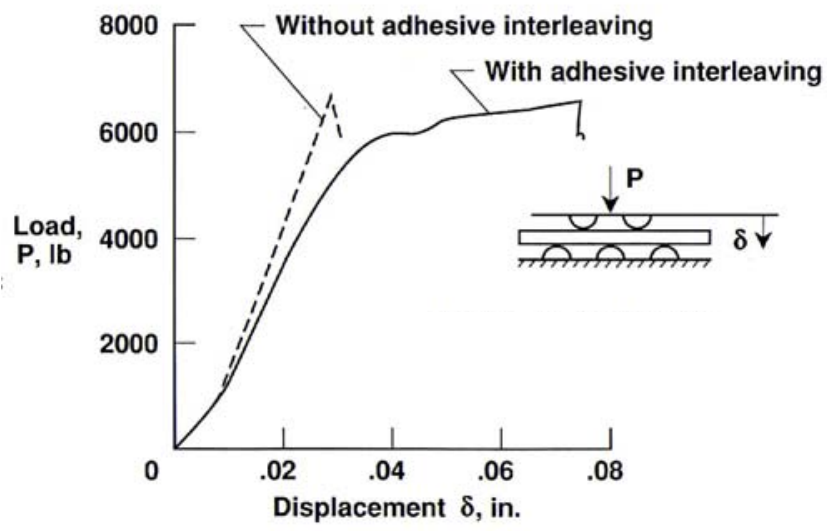

c) Typical load-displacement relationship. Figure 3. Multi-span beam shear test. 


\section{Simple Plates and Shells}

Evaluating the behavior of damaged structures is part of any design process. Structures must withstand damage due to tool drops, hail stones, runway stones, and engine damage resulting in thrown debris. Compression after impact, tension after impact, flat and curved panels with holes or sawcut-type damage and with pressure, shear and combined loadings in the presence of damage all have to be considered. Typical impact experimentation is done by inflicting damage to a panel by dropping weights or shooting projectiles at it at specified velocities to inflict damage, and then loading the panels to study its response. A typical flat panel in the test fixture is shown in Fig. 4a and the resulting series of results of strain at failure versus impact energy for compression-loaded graphite-epoxy panels is shown in figure $4 \mathrm{~b}$. In this case, graphite-epoxy panels (represented by circles) and graphite-thermoplastic panels (represented by squares) were evaluated to determine the improvement in damage tolerance by using a thermoplastic resin. ${ }^{48}$ Panels were first impacted by shooting a 0.5 -inch diameter aluminum sphere at the center of the panel then each panel was loaded to failure in compression. The axial strain in the panel at failure was recorded. The improvement in performance can be seen by noting that the thermoplastic panels have higher axial strain at failure than the graphite-epoxy panels for each impact energy considered.

Similar studies were conducted for panels subjected to pressure or shear loadings in the presence of impact or discrete source damage. Discrete source damage can result from debris like fan blades being thrown through a wing or fuselage skin. Such damage can sever a stringer, frame or other stiffening element, supporting the need for clear understanding of changing load paths and load redistribution.

Curvature can also influence the panel behavior. Cylindrical panels and full cylinders must be tested and analyzed to predict their behavior. A typical cylinder subjected to compressive loading past the initial buckling load is shown in Fig. $5 \mathrm{a}^{49}$ A shadow moiré interforometry technique was used to capture the out-of-plane displacement pattern shown. Finite element analysis using the Structural Analysis of General Shells (STAGS) ${ }^{50}$ computer code was used to predict the initial buckling load and the post-buckling behavior. The corresponding buckle pattern predicted for this cylinder is shown in Fig. 5b. The black curves represent the contours of the out-of-plane displacement predicted.

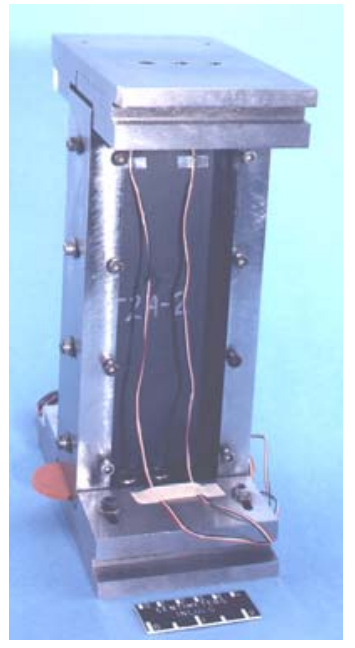

a) Impact panel prior to testing.

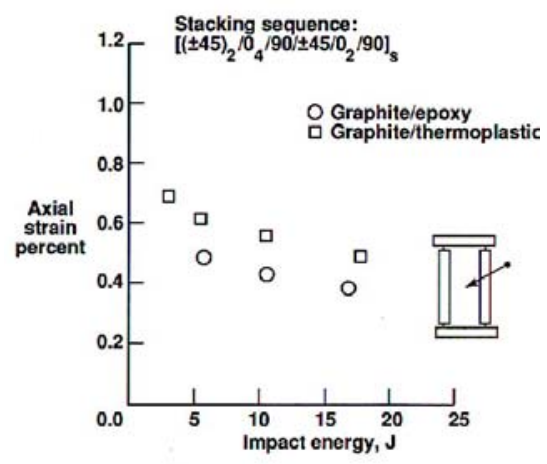

b) Failure strain.

Figure 4. Impact damage evaluation

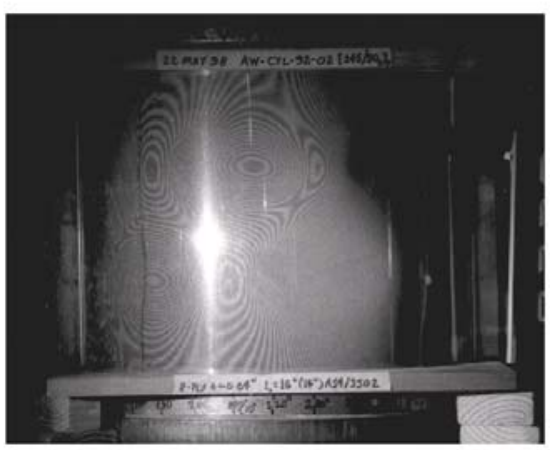

a) Experimental post-buckling deformations.

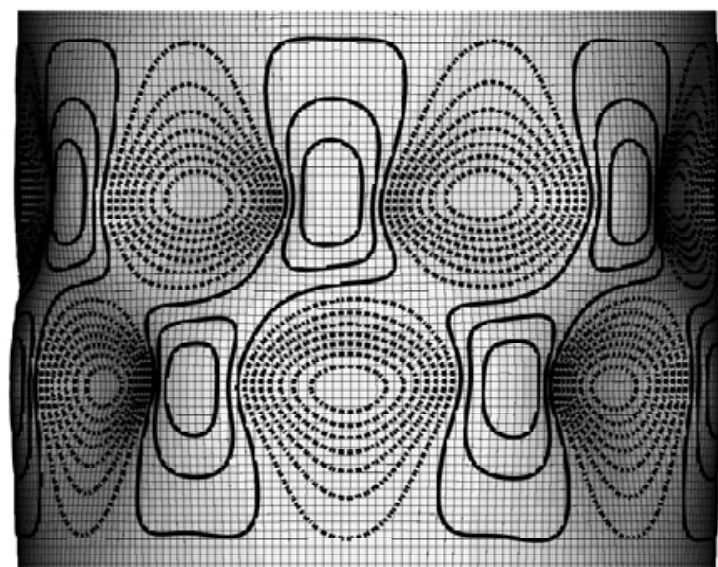

b) Predicted post-buckling deformations.

Figure 5. Typical compression-loaded cylinder. 


\section{Focused Technology Development Programs}

There were two parts to Phase C of the ACT program. NASA and McDonnell Douglas Aerospace (now Boeing Phantom Works) were to address technologies applicable to the wing of the airplane, while NASA and Boeing were to address technologies applicable to the fuselage. Differences in structural and manufacturing requirements for the wing and fuselage meant that these parts of the aircraft would require different approaches to achieve the goals of the program; however, the high stiffness and light weight of composite materials made composites the obvious choice for both parts of the program. The first step in addressing the goals of the ACT program was to select the most promising material system and manufacturing technique. For the wing program, through-the-thickness stitching was selected to improve the damage tolerance of the wing by reducing damage growth and reduce part count by eliminating the need for rivets by stitching the stiffeners to the skin. A resin film infusion technique was selected to be cost-efficient and allow for the infiltration of resin into the stitched perform. For the fuselage program, a skin/stringer configuration was selected for the crown quadrant of the fuselage and sandwich configurations were selected for the side and keel quadrants of the fuselage. The stiffened-skin configuration consisted of skin that was fabricated using automated fiber placement. The hat section stringers were fabricated using a tape laying machine and cocured to the skin. The circumferential frames were J-section braided resin transfer molded and cobonded to the skin.

The approach used in the HSR program was to integrate design requirements from various disciplines leading to the development of wing and fuselage structural concepts. Analysis and sizing methodologies were developed for combined thermal and mechanical structural loads and then these methodologies were verified by test. Selected structural concepts were verified by test using a building-block approach from coupons to structural elements to components. These concepts were more structurally efficient and cost effective than state-of-the art aircraft structures. Materials durability testing was conducted to determine the durability of metallic and composite materials subjected to supersonic vehicle loadings. Also, accelerated tests method were developed to study the long term effects of composite structures subjected to thermal and mechanical loading. The prime industry partners in the HSR program were Boeing, McDonnell Douglas Aerospace, and Northrop-Grumman.

\section{A. ACT Wing Program}

After the basic concept development work was completed in Phase A of the ACT program, the followon work was focused on either a wing or fuselage. McDonnell Douglas focused on developing the technology and verification work needed to promote the use of a composite wing on a 220-passenger commercial transport aircraft. In addition to the typical material characterization activities, since the new stitching technology was to be employed in the ACT wing program, small flat panels were built to define the stitching requirements. These small specimens were used to determine how many stitches per inch were needed to prevent damage growth under tensile or compressive loading and then to determine the influence of the stitches on the material in-plane properties. Specimens were then built to investigate the ability of stitches to hold stiffener flanges to the panel skin in the presence of shear or tensile loads. In addition to stitching, a Resin-Film-Infusion (RFI) process was developed to simplify the infusion process for large structures. Characterization studies were conducted to quantify the behavior of these RFI specimens.

In order to develop a full-scale stitched composite wing, the next step in the building-block approach was to look at "Design Development Test Articles." These articles included multistringer panels with access door holes, 2-bay discrete source damage, spliced stringer repairs, tension and compression loading changes in skin thicknesses, and specimens focusing on the landing gear region, shear-loaded spars and stiffener

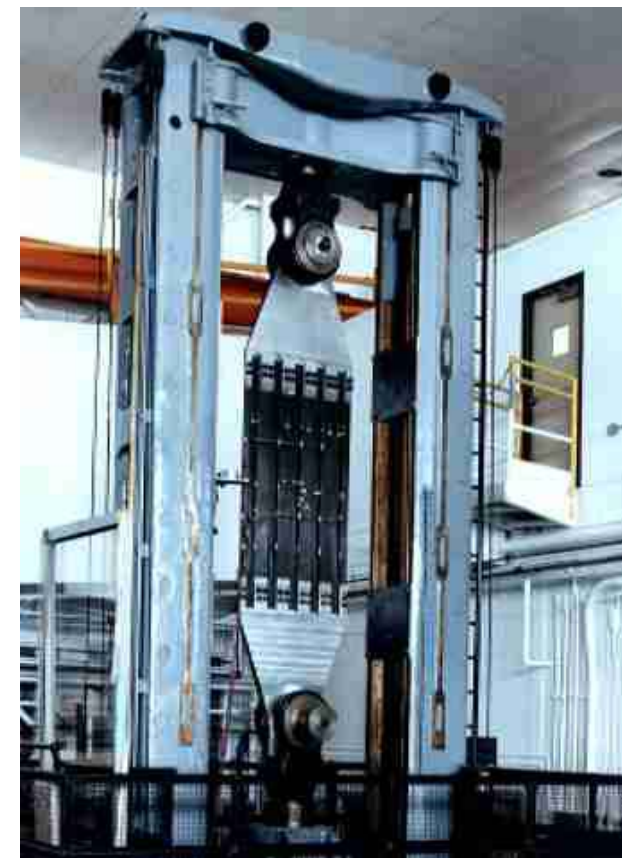

Figure 6. Tension-loaded design development test article. 
terminations. ${ }^{9,11,13}$ A 40-inch-wide, 10-foot-long 5-stringer panel subjected to discrete source damage and tensile loading is shown in figure 6. This panel was subjected to a series of tests leading up to an evaluation of its ability to withstand loading in the presence of discrete source damage. Discrete source damage can result from debris like fan blades being thrown through a wing or fuselage skin. Such damage can sever a stringer, frame or other stiffening element, requiring the need to develop a clear understanding of changing load paths and load redistribution supported by both testing and analysis. This tension panel failed through the damage site at a load of $140 \%$ of Design Limit (DLL), twice that required by the FAA for commercial transport aircraft with this type of damage.

A similar 5-stringer panel with a bolted patch repair to be loaded with compressive loading is shown in Fig. 7. Repairs involving patching the skin and spicing a severed stringer can be performed with little equipment. The panel shown in Fig. 7 supported a load greater than Design Ultimate Load (DUL = $1.5 * \mathrm{DLL})$ when loaded in compression.

Also in this phase of the program was the need to prove that a full scale wing box could be built and that it would withstand the necessary loading conditions. The progression through the building-block approach next led to the design of a subscale wing box, also known as the stub box. In designing the stub box, design details such as stiffener runouts, changes in skin thicknesses and the interaction of these design details with impact damage were examined. In each case, a detailed finite element model was created to predict the failure load, mode and location. To build wing cover panels, automated stitching technology had to be developed and a resin film infusion method refined to allow the manufacturing goals to be met. Building the "stub box" was a challenge in itself because each cover panel was larger than any piece of stitched structure previously built. Nevertheless, the 12-foot-long, 8foot-wide stub box with all-composite cover panels, ribs and spars was constructed using the stitched resin film infusion

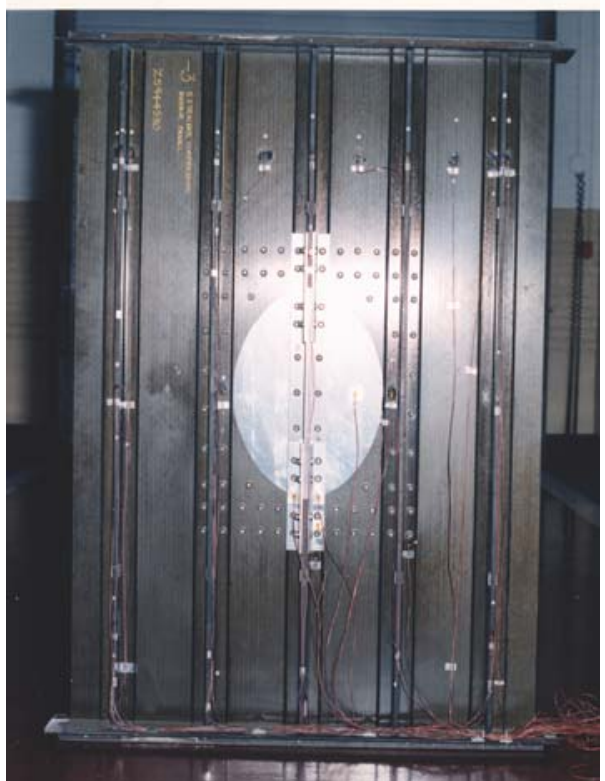

Figure 7. Compression-loaded repair panel panel. technology and loaded in a way to simulate a $2.5 \mathrm{G}$ pull-up flight maneuver.

The wing-stub-box test article consists of a metallic load-transition structure at the wing root, the composite wing stub box, and a metallic extension structure at the wing tip, as shown in Fig. 8. The loadtransition structure and the wingtip extension structure are metallic end fixtures required for appropriate load introduction into the composite wing stub box during the test. The loadtransition structure is located inboard of the composite wing stub box (between the composite wing stub box and the vertical reaction structure at the wing-stubbox root), and the wing-tip extension structure is located outboard of the composite wing stub box. The load-transition structure is mounted on a steel and

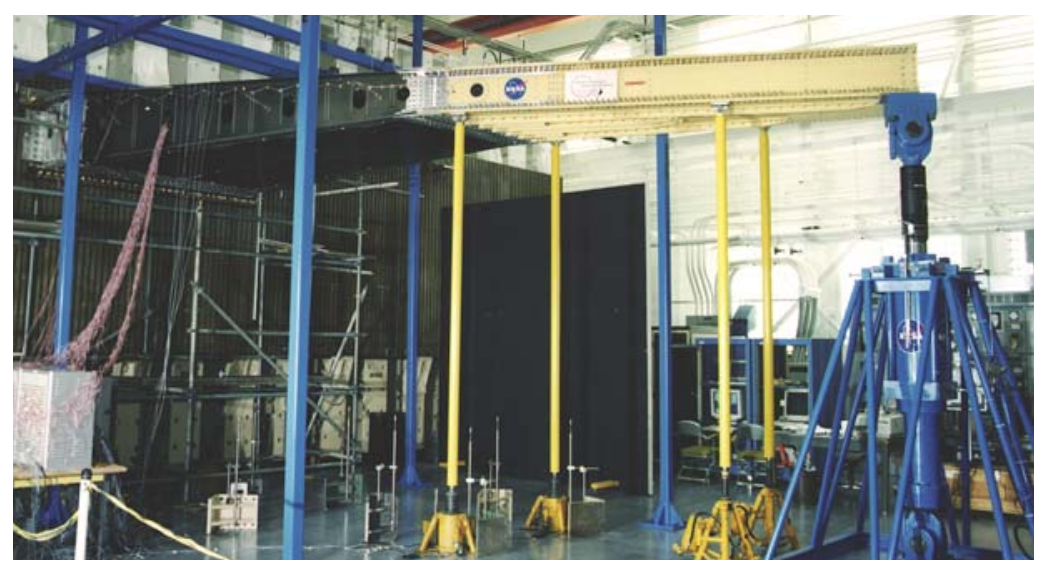

Figure 8. Wing stub box prior to testing.

concrete vertical reaction structure resulting in a nominally clamped end condition. A 300-kip actuator was positioned under the tip of the metal extension box. A series of four tests were conducted where the structure was loaded with and without impact damage. Prior to the final test, the stub box was subjected to drop weight impacts with $100 \mathrm{ft}-\mathrm{lb}$ energy, causing barely visible impact damage. Failure occurred at a load of 154 kips, which corresponds to $93 \%$ of DUL. Failure occurred though a known impact-damage site near a stiffener termination on the upper cover panel, as shown in Fig. 9. The success of the stub box tests 
led to moving on to the next step in the program, the fabrication, analysis and testing of a full-scale stitched RFI semi-span wing.

A major effort in fabricating the semispan wing test article was to use the stitched resin-film infusion manufacturing technique to build a series of 40 -foot-long stiffened panels with complex curvature. Two of these panels were assembled together with spars, ribs and load introduction structures to create a semi-span wing box representing the first 40 feet out from the root of a 220 passenger commercial transport aircraft wing. A detailed finite element analysis of the semi-span wing box was conducted using the STAGS computer code to understand behavior at design details such as stiffener runouts, splices and unsupported regions. Nine actuators were used to subject the wing

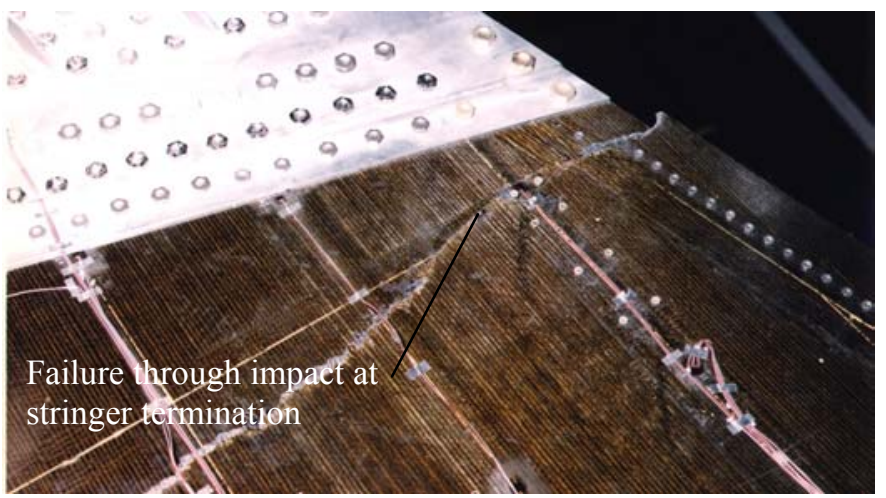

Figure 9. Failed upper cover stub box panel. box to a series of loadings including a brake-roll condition in which load was introduced through a simulated landing gear leg, a pull down flight condition of $-1 \mathrm{G}$ and a pull up flight conditions of $2.5 \mathrm{G}$. During this series of tests, discrete source damage was inflicted to both the upper and lower cover panels, the wing subjected to DLL, and the damage repaired. Prior to the final test, the upper and lower cover panels were each subjected to three 100 -ft-lb impacts to cause barely visible damage at critical locations. In the final test the semi-span wing was subjected to loading in the $2.5 \mathrm{G}$ upbending condition. The wing box supported $97 \%$ of DUL prior to failure through a lower cover panel access door. A photograph of the wing box subjected to $95 \%$ of its DUL in the $2.5 \mathrm{G}$ loading condition is shown in Fig. 10a. The finite element model of the wing box is shown in Fig. 10b. This model contains approximately 71,000 nodes, 76,000 elements and 428,000 degrees of freedom. A comparison of test data and predictions of deflections are shown in Fig. 10bc and the failure across the lower cover panel is shown in Figure Fig. 10d.

By withstanding $97 \%$ of DUL in the most severe loading condition and in the presence of damage and repair, the stitched wing program was declared a successful technology development program and NASA turned further development over to industry. Further information about the stitched semi-span wing test program can be found in references 23-25.

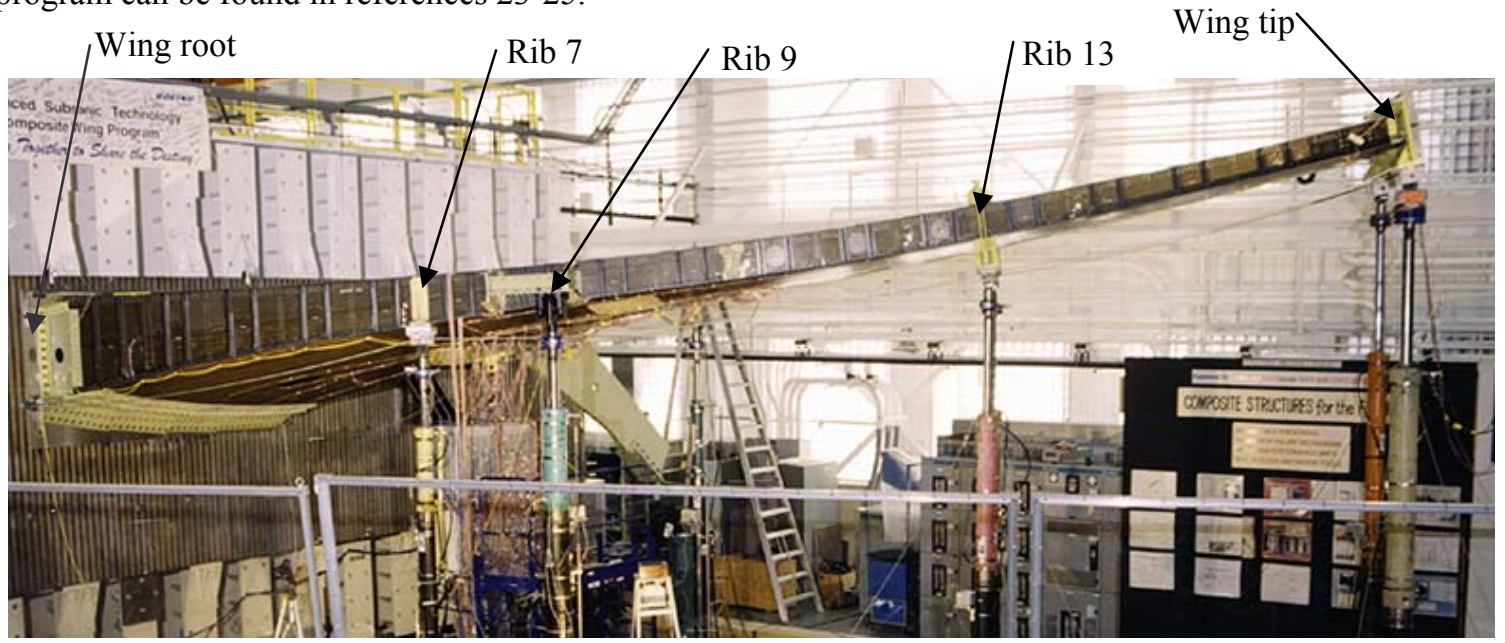

a) Stitched semi-span wing subjected to $95 \%$ design ultimate load. 


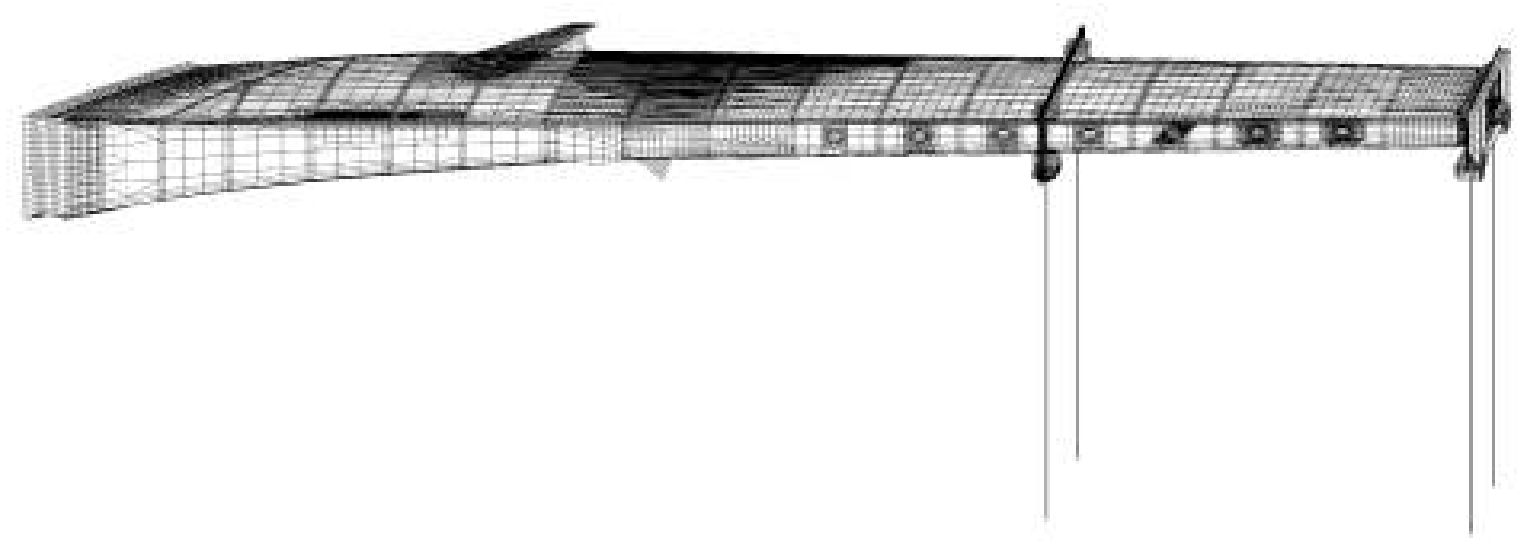

b) Finite element model.

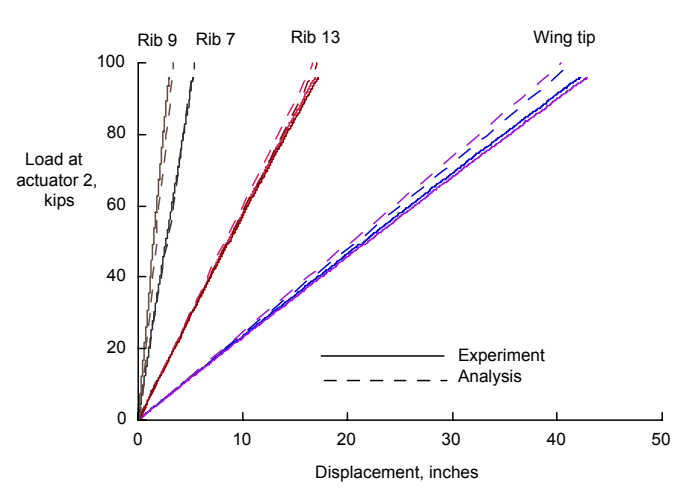

c) Measured and predicted displacements at load points.



d) Failure across lower cover panel. Figure 10. Stitched semi-span wing.

\section{B. ACT Fuselage Program}

The primary objective of the ACT fuselage program was to develop composite primary structure for commercial airplanes with $20-25 \%$ less cost and $30-50 \%$ less weight than equivalent metallic strucuture. In order to develop advanced structural concepts for aircraft fuselage, a pressurized aft fuselage section of a wide body generic wide body airplane with a diameter of 244 inches was chosen as the area of study for development of composite fuselage structural concepts. This section was chosen since it contained most of the structural details and critical manufacturing issues present in fuselage structures. The fuselage section was divided into four circumferential quadrants, the crown, the left and right sides, and keel. Details of the aft fuselage section are described in Fig. 11. A three step approach was used to identify and evaluate structural concepts for each quadrant of the fuselage section. First, the baseline concept selection was determined to be the concept that was judged to have the greatest potential for cost and weight savings with considerations for acceptable risk. Second, a global evaluation was conducted to develop preliminary designs in sufficient detail such that cost and weight differences between the baseline concept and other low-cost/low-weight concepts could be developed. The final step involved selecting the concepts with the largest weight-saving potential for local optimization. This step involved optimizing the design elements while considering the impact of any design changes on overall cost. This approach resulted in a skin/stringer configuration for the crown quadrant and sandwich construction for the keel and side quadrants $^{34}$. 
Structural stability was also an important consideration for evaluating structural concepts for fuselage structures. Overall cylinder buckling was a consideration for all quadrants of the fuselage section as well as local and torsional buckling of the circumferential frames. Local skin buckling and column buckling of stringers were were also assessed. Facesheet wrinkling, dimpling, and crimping were considered for side and keel structures. A series of buildingblock tests were conducted to evaluate the structural stability of crown fuselage concepts. Crippling test were conducted on single skin/stringer elements to understand the local stability behavior of stringers. Finally, three-stringer panels with two frames and five-stringer panels with four frames were tested to evaluate the skin buckling. The effect of barely visible impact damage on the buckling and failure behavior was also studied during the tests.

\section{Fuselage Crown Panel Evaluation.}

A series of benchmark crown panels were formulated to gain additional understanding of the structural

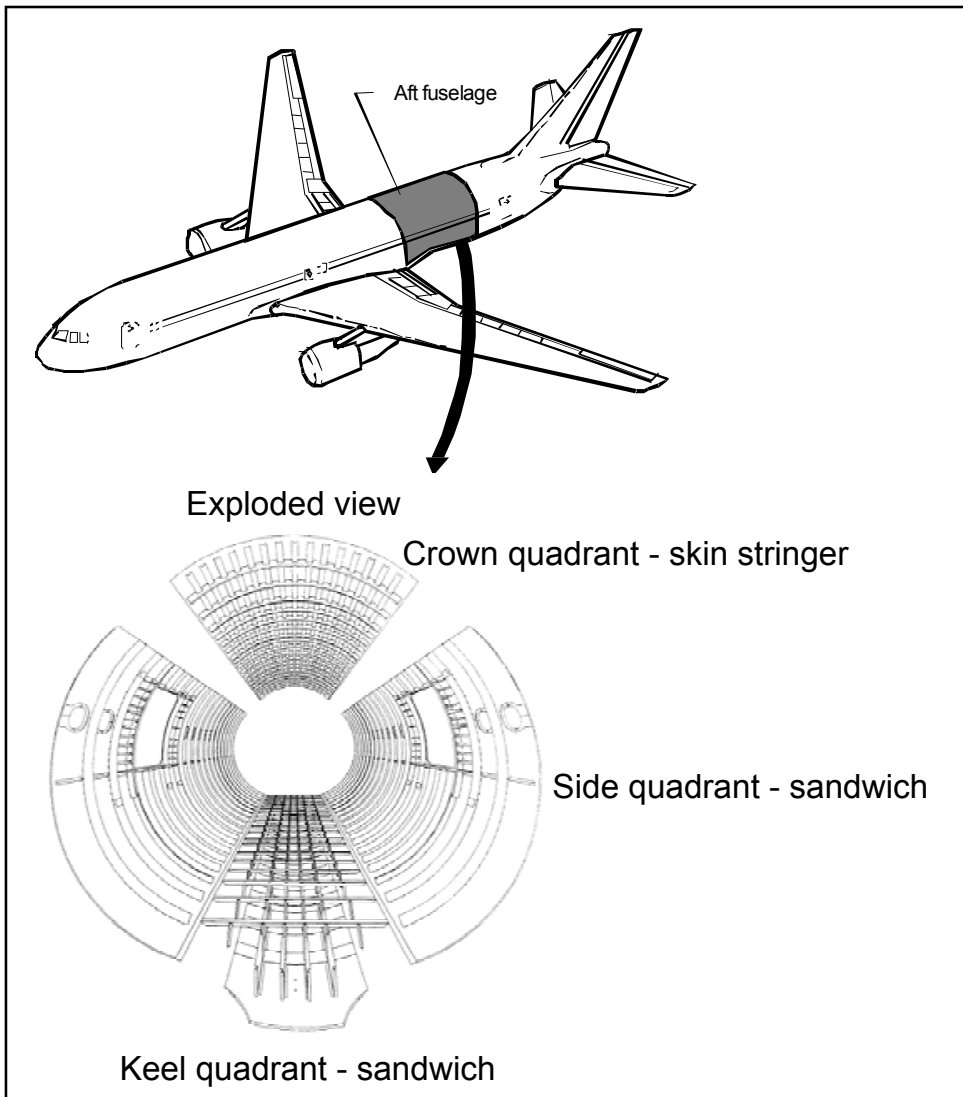

Figure 11. Transport aircraft wide body fuselage structure. performance of thin gage fuselage structures fabricated from composite materials. Five curved stiffened panels representative of fuselage crown design concepts were fabricated to provide test specimens for a pressure-box test fixture (described subsequently) and for frame/skin bondline strength evaluations. These panels also provided the opportunity to investigate alternate design concepts in addition to alternate damage scenarios such as circumferentially-oriented notches and barely visible impact damage. A summary of the different panel configurations is given in Table 1. A photograph of a typical benchmark crown panel is shown in Fig. 12. The stiffened graphiteepoxy fuselage crown panel shown in Fig. 12 was tested in a pressure-box test machine to study its response characteristics when subjected to internal pressure and biaxial tension. The panel has a 122 -in. radius, a 72 -in. length, and a 63-in. arc width. The material type and material properties for this panel are presented in Ref. 35. The panel skin is tow-placed using a fiberglass-graphiteepoxy hybrid material system to improve the damage tolerance characteristics of the panel. The panel frames are made of triaxially braided graphite fiber preform impregnated with an epoxy resin and cured using a Resin Transfer Molding process. The stringers pass through cutouts machined into the frames, and no clips are used to attach the stringers to the frames. This design detail reduces the structural part count and the cost associated with panel

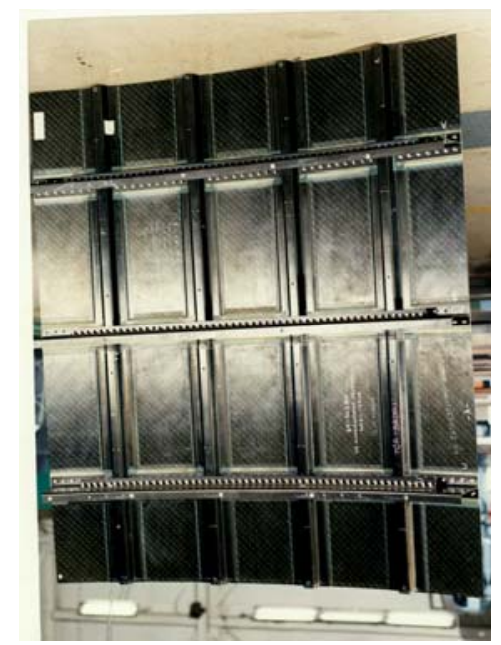

Figure 12. Photograph of a typical benchmark crown panel. fabrication. 
Table 1. Summary of benchmark crown panel tests.

\begin{tabular}{|l|l|l|l|l|}
\hline \multirow{2}{*}{$\begin{array}{c}\text { Panel } \\
\text { Designation }\end{array}$} & \multicolumn{1}{|c|}{ Ultimate } & \multicolumn{1}{c|}{ Limit } \\
\cline { 2 - 5 } & $\begin{array}{l}\text { Load Case } \\
\text { pressure }\end{array}$ & None 5 Damage & $8.85 \mathrm{psi}$ & Severed skin/frame \\
\hline TCAPS 1 & $\begin{array}{l}\text { Combined 13.8 } \\
\text { psi pressure } \\
\text { and 5,000 lb/in } \\
\text { tension }\end{array}$ & $\begin{array}{l}\text { Failed due to critical } \\
\text { damage at frame/skin } \\
\text { interface }\end{array}$ & $\begin{array}{l}\text { Combined } 8.85 \\
\text { psi and 3,370 } \\
\text { lb/in }\end{array}$ & \\
\hline ATCAS 12 & $\begin{array}{l}18.2 \mathrm{psi} \\
\text { pressure }\end{array}$ & None & $8.85 \mathrm{psi}$ & Severed skin/frame \\
\hline TCAPS 4 & $\begin{array}{l}\text { 18.2 psi } \\
\text { pressure }\end{array}$ & None & $8.85 \mathrm{psi}$ & Severed skin/frame \\
\hline TCAPS-3 & $\begin{array}{l}\text { 18.2 psi } \\
\text { pressure }\end{array}$ & $\begin{array}{l}\text { Low-speed impact } \\
\text { damage }\end{array}$ & $\begin{array}{l}8.85 \mathrm{psi} \text { cycle } \\
\text { loading }\end{array}$ & $\begin{array}{l}\text { Low-speed impact } \\
\text { damage }\end{array}$ \\
\hline
\end{tabular}

As part of the ACT fuselage program, several curved panels were fabricated by Boeing Commercial Airplane Group and tested in a specially designed pressure-box test fixture. The fixture is capable of testing curved panels subjected to internal pressure and bi-axial tension by using axial actuators and turnbuckle or hoop restraint rods. This fixture is described in Refs. 51 and 52. A photograph of the

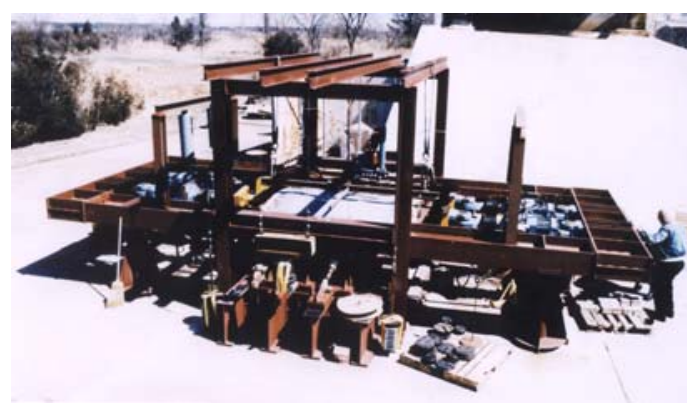

Figure 13. Photograph of pressure-box test fixture.

pressure-box test fixture with a curved panel subjected to internal pressure were performed using the STAGS finite element code. The analysis of the cylindrical shell ensured that the load state that was applied to the pressure-box

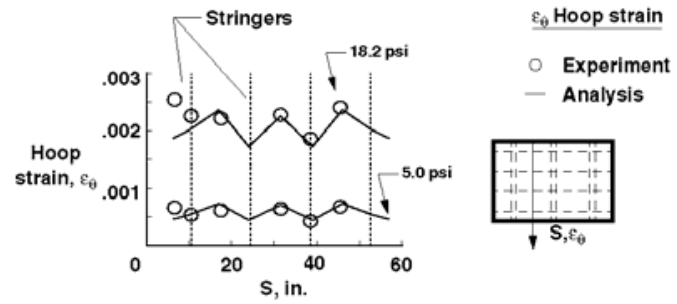

b) Comparisson of analytical and experimental hoop strain results Figure 14. Finite element model of crown panel. pressure-box test machine is shown in Fig. 13. In support of these tests, nonlinear structural analyses of a cylindrical shell with internal pressure as well as the

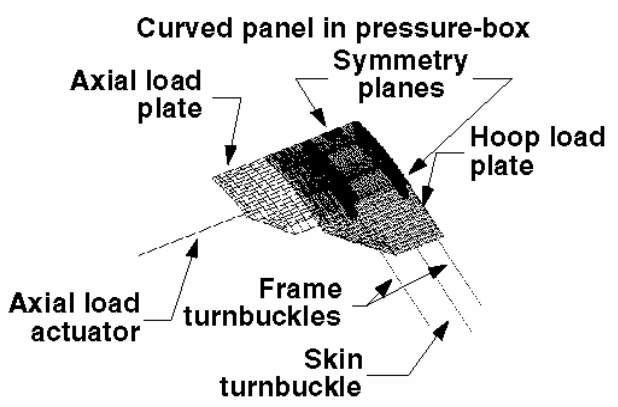

a) Finite element model of crown

panel.

panel was representative of that in a full cylinder. A quarter model of the pressure-box test fixture with a curved panel has been developed for analysis using shell, rod, and beam elements as shown in Fig. 14. The turnbuckles or hoop restraint rods and hydraulic actuator rods are also included in the model to account for their rigid-body rotational degrees of freedom as the panel translates when internally pressurized. This model has approximately 10,000 elements with approximately 62,000 degrees of freedom. The experimental hoop strain results along an axis oriented in the axis s from the experiment are compared with analysis results in Fig. 14 for a 
fuselage panel subjected to internal pressure conditions of 5 psig and 18.2 psig in the pressure box test fixture. The correlation between the results is excellent. This comparison suggests that the finite element model represents the test well.

\section{HSR program}

As part of the HSR fuselage program, several sizes of structural specimens were fabricated to support the development of stiffened-skin concepts for the fuselage structure. Specimens ranged from simple stiffener pull-off and stiffener crippling specimens to full-scale panels designed for vehicle loads. Examples of stiffener pull-off and stiffener crippling specimens are given in figures 15 and 16, respectively. A typical stiffener pull-off specimen is shown in Figure 15(a), and a typical stiffener pull-off failure mode is shown in figure 15(b). These tests were used to verify the integrity of the skin-stiffener interface, which is important in postbuckled designs as well as fuselage over-pressure

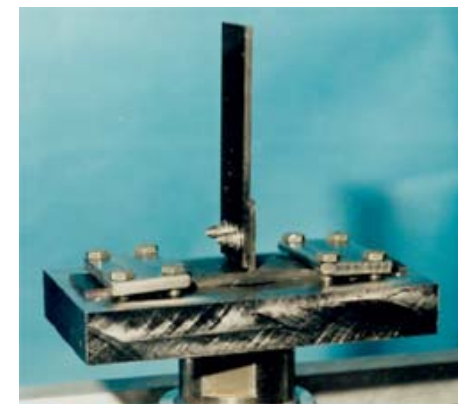

(a) stiffener pull-off specimen.

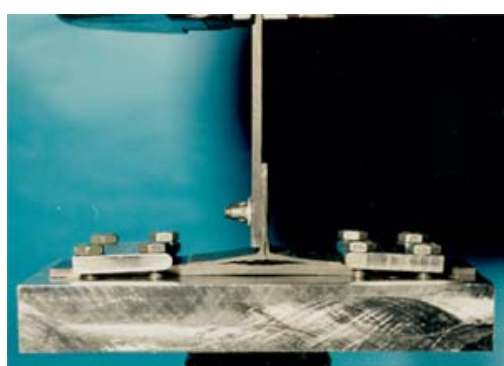

(b) Stiffener pull-off failure mode

Figure 15. Typical stiffener pull-off specimen and test.

crippling specimen is shown in Figure 16(a), and a photograph of of the shadow moiré interferometry outof-plane displacement pattern at an applied load of 33.6 kips is shown in figure 16(b). These tests were used to investigate the stability of the stiffener design and to understand the strength characteristics of the skin-stiffener combination.

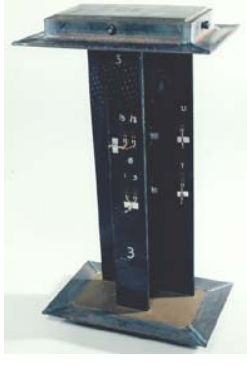

(a) stiffener crippling

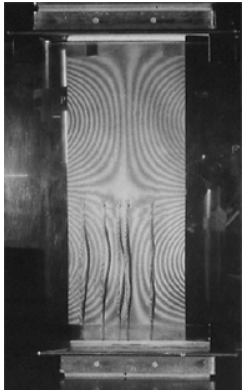

(b) out-of-plane displacement

Figure 16. Typical stiffener crippling specimen and test. 

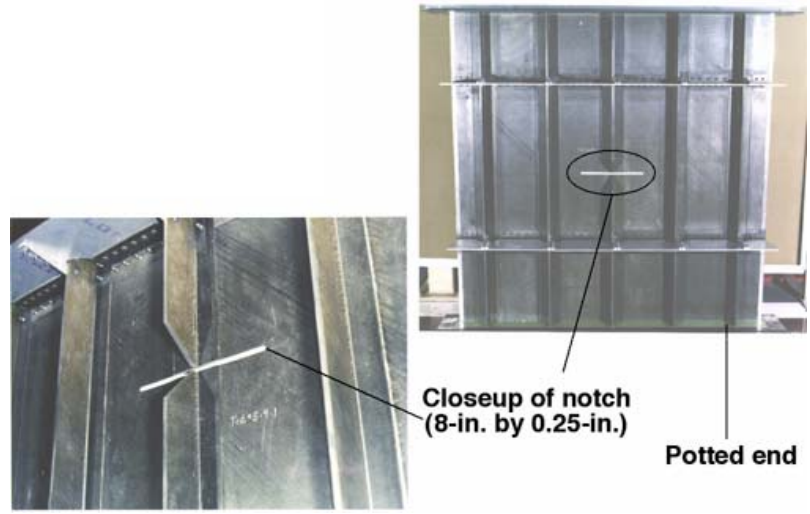

(a) Five-stringer2-frame notched-compression subcomponent

Following these element tests, a series of sub-

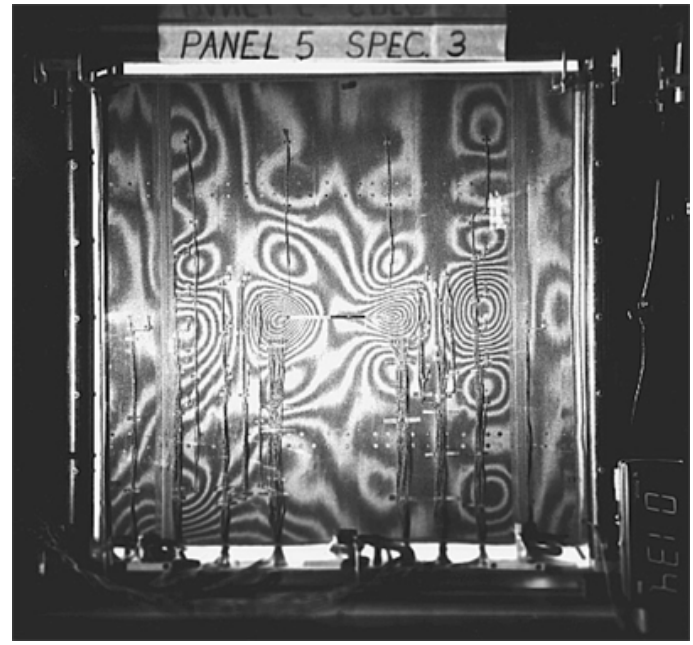

c) An experimental out-of-plane displacement pattern at an applied load of 134 kips.

component scale panels were tested. The panels were tested in uniaxial compression to evaluate the response of the different skin layup designs as well as the effect of impact damage and discrete-source damage. Experimental and analytical results are compared in Fig. 17 for a compression sub-component panel built for the HSR fuselage program by McDonnell Douglas Aerospace (now Boeing Phantom Works Division). The sub-component panel is shown in Fig. 17a and it measures 40 -in-wide by 40 -in-long and has five stringers spaced at 8 inches and two frames located 10 inches above and below the horizontal centerline of the panel. There is an 8 -in-long by 0.25 -in-wide machined notch through the center stringer to simulate discrete-source damage. Knife-edge supports were applied to the unload edges, and frame restraints were used to restrict global bending response. The loaded edges were encased in potting material and machined flat and parallel to each other. A geometrically nonlinear structural analysis of this subcomponent was also performed using the STAGS finite element code. The finite element model used for the analysis, shown in Fig. 17b consists of 3,596 nodes, 3,492 shell elements, and 21,776 active degrees of freedom. A photograph of the shadow

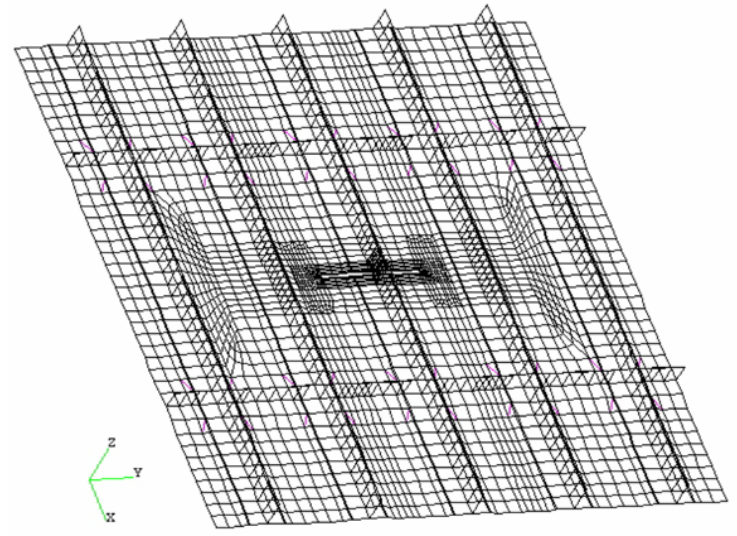

b) Finite element model of the notched 5-stringer subcomponent panel.

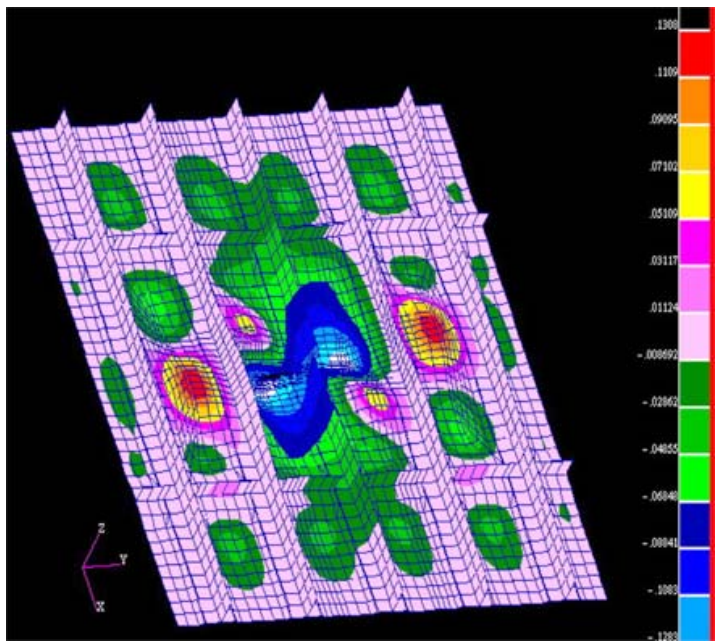

d) An analytical out-of-plane displacement pattern at an applied load of 138 kips.

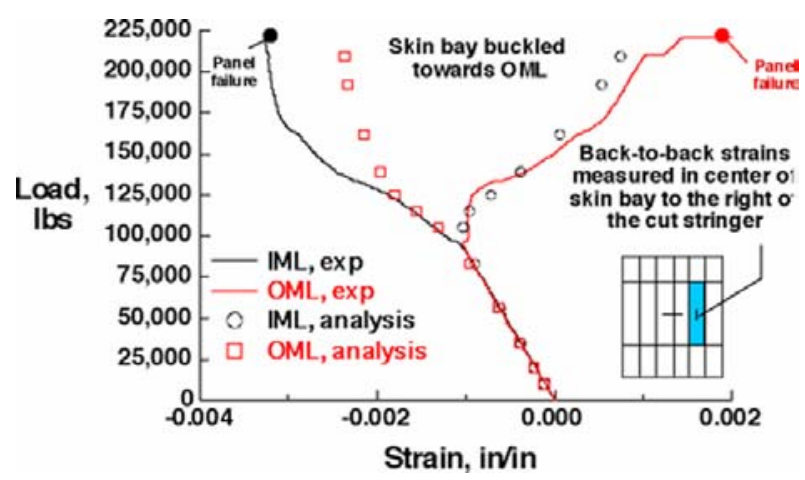

e)Comparison of surface strain results in a skin-bay adjacent to the cut skin bay.

Figure 17. Typical results for a HSR fuselage panel loaded in compression. 
moiré interferometry out-of-plane displacement pattern at an applied load of 134 kips is shown in Fig 17c. The out-of-plane displacement contours at an applied load of 138 kips predicted using the STAGS analysis are shown in Fig. 17d. The correlation between the measured and predicted displacement patterns is very good. A comparison between measured and predicted load versus surface strain results in a skin bay adjacent to the cut skin bay is presented in Fig. 17e. The good correlation between the experimental values (i.e., the solid lines) and the predicted values (i.e., the open symbols), suggest that the analysis model represents the test well. Failure is indicated by the filled symbols.

The results from these element and sub-component tests were then utilized by McDonnell Douglas to design full-scale fuselage panel test articles to be tested under uniaxial loads in an un-pressurized configuration. Both tension and compression full-scale fuselage panels were designed and tested. One of the five-stringer fuselage panel tension test articles is shown in figure 18. These test panels were 80inches-long and 40-inches-wide, and had an eight-inch stringer spacing. A special load introduction fixture was designed by McDonnell Douglas to directly introduce load into the stringers. The purpose of the tension test series was to evaluate the adequacy of the skin-stringer design to support the required design

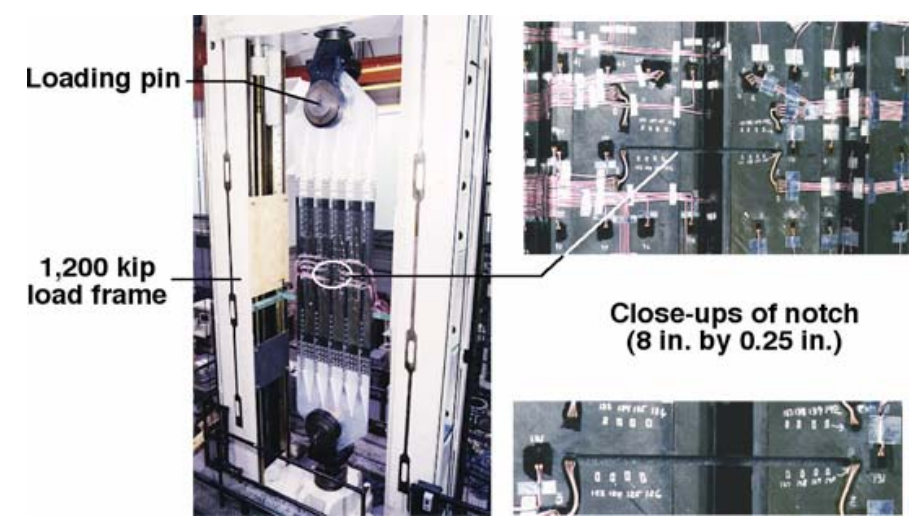

(a) Tension panel and notch detail

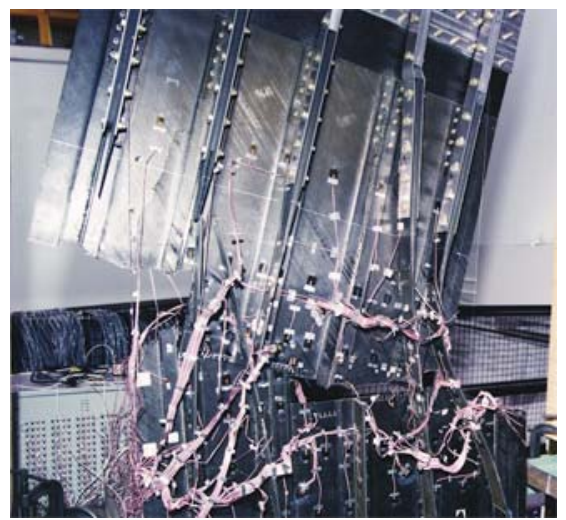

(b) Failure mode of tension panel

Figure 18. Five-stringer fuselage tension panel with discrete source damage.

loads in the presence of discrete source damage. The discrete source damage was simulated with a notch that was machined through the center stringer and spanning one full skin-bay width. A typical test panel is shown in the 1.2 million-pound test machine at NASA Langley in figure 18. A close-up of the notch is also shown in figure 18(a), and the failure mode of the panel is shown in figure 18(b). The failure initiated at the notch tip, propagated to the adjacent stringers, and then ran parallel to the stringers causing failure of the panel. The panel supported all design loads.

The final full-scale fuselage compression panel tested in this series of tests is shown in figure 19. This curved panel is 120-inches-long with an arc length of 60 inches and a radius of curvature of 60 inches. This panel was tested in uniaxial compression to assess its stability characteristics and to study its response in the presence of both barely visible impact damage as well as discrete source damage. A photograph of

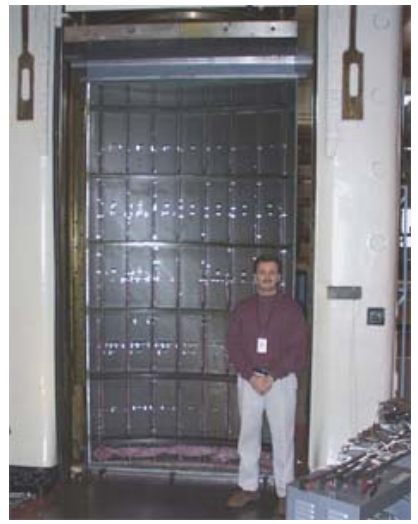

(a) Panel in test machine

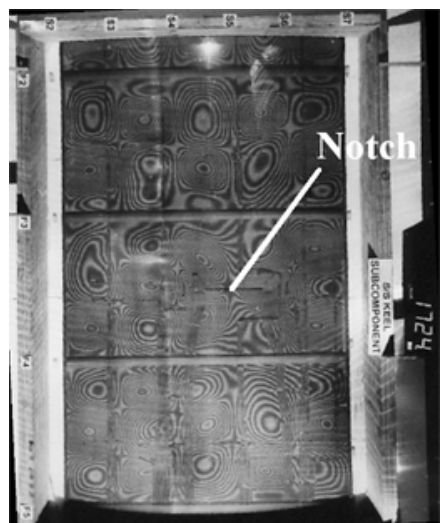

(b) Out-of-plane displacement contours (172.4 kips)

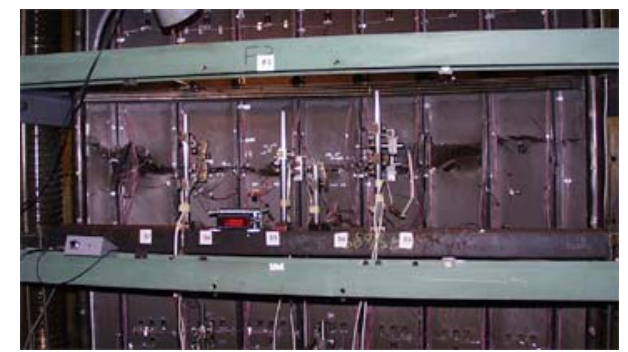

(c) Panel failure mode

Figure 19. Five stringer fuselage compression panel with barely visible impact damage and discrete-source damage 
the shadow moiré interferometry out-of-plane displacement pattern just prior to failure at an applied load of 172.4 kips is shown in Fig 19b. The location of the notch is shown in this figure as well. The panel was well into the post-buckled range at this load level. The failure mode of the panel is shown in figure 19c. The failure initiated as a local failure at the notch tip in the post-buckled configuration and then propagated across the width of the panel. This panel supported all required design loads as well.

Combined Loads Test HSR Fuselage Panels

A majority of the testing conducted in the HSR Program consisted of coupons, elements and panels. These building-block tests were used to develop material property database that could be used to size and

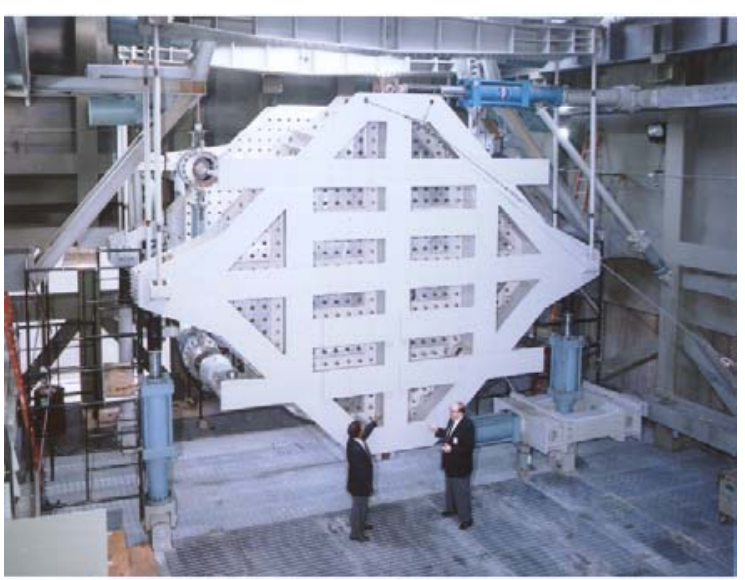

Figure 20. NASA combined loads test machine. analytical predict the responses of larger structures. However, large full scale panels with sufficient details were tested in order to validate structural concepts. Some typical results for composite curved fuselage panels that were tested in the Combined Loads Test machine (COLTS) will be described in this section.

The combined loads test machine and D-box test fixture configurations are illustrated in Fig. 20. The details of the combined loads test machine are summarized in Ref. 53. The D-box test fixture was designed to ensure that appropriate boundary conditions are imposed on a curved panel to provide a stress state that is representative of a cylindrical shell. This requirement is particularly important when investigating the failure of a curved panel.

The D-box test fixture shown in FIg. 21a was used to apply mechanical and internal pressure loads to the test panel. The small axial stiffness of the D-box test fixture allows a test panel to experience most of the applied axial load and minimizes the shift in the center-of-pressure of the assembly if the test panel buckles. The low axial stiffness of the D-box test fixture is the result of an assembly of curved I-beams with the cross-section shown in the inset. The I-beam sections are 8.0-inches deep and 15 of these sections are used to make the D-box test fixture. This D-box test fixture is designed to test curved panels with 60to 130-inch radii and 20- to 22-inch frame spacings. The panels are attached to the D-box test fixture with the hinge fittings as indicated in Figure 21b. A cross-section of the D-box test fixture is presented in Fig $21 \mathrm{~b}$ that shows the details of the hinge fittings. Thirteen of these hinge fittings are provided between the Ibeams for this purpose. When the D-box assembly is internally pressurized, the assembly expands in a manner that causes the hinge supports to move inward. This deformation will cause the test panel to bend in a way that is not representative of the response of an internally pressurized shell. To prevent this undesirable deformation, cross bars are mounted between the hinge points as shown in the figure such that the distance between the hinge points can be held constant or adjusted as needed to induce the appropriate

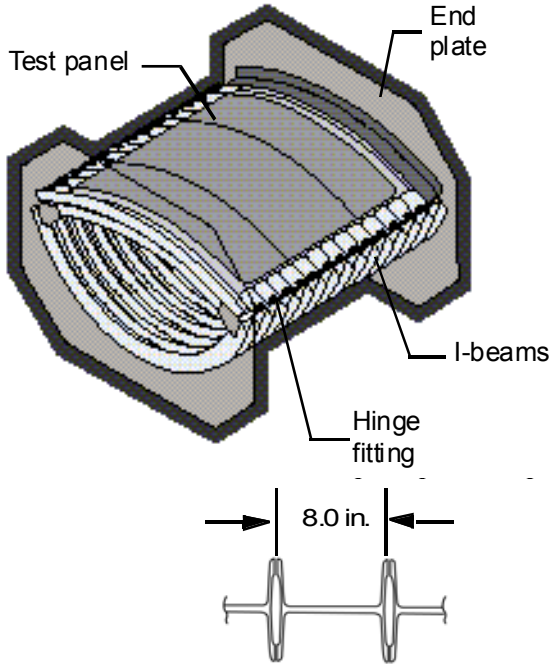

a) Overall configuration

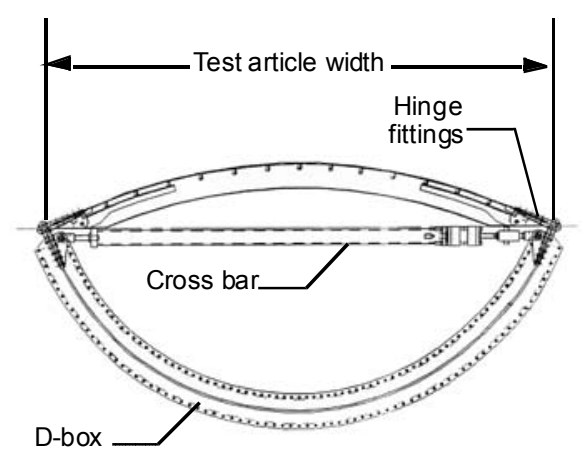

b) Cross-sectional view

Figure 21. D-box fixture for testing curved stiffened panels. 


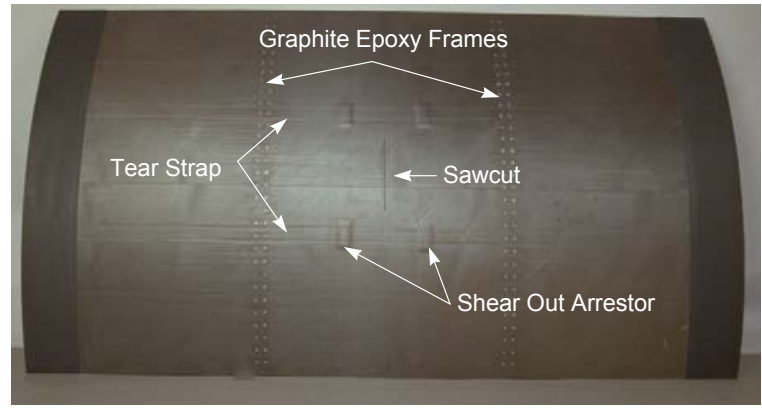

Figure 22. Photograph of curved sandwich fuselage panel.

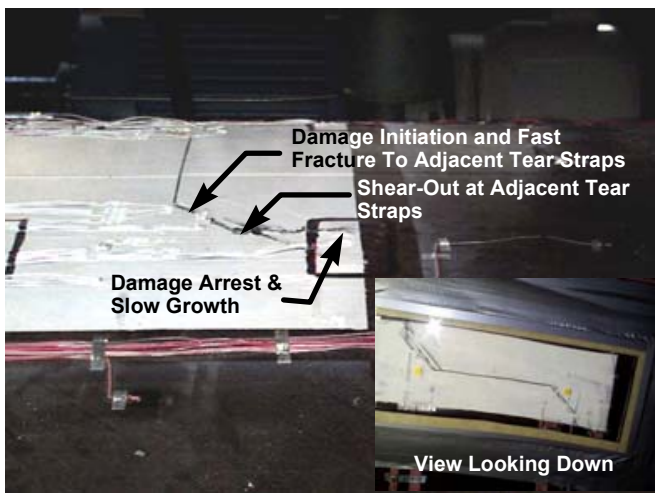

Figure 23. Photograph of failed fuselage panel.

stress state in the test panel. A detailed description of the D-box test fixture is presented in Ref. 53.

A curved sandwich fuselage panel with a centrally located circumferential sawcut through the facesheet and honeycomb core of the panel was subjected to internal pressure, shear and axial loading using the Dbox test fixture in the COLTS combined loads test machine (Ref. 54). The sandwich facesheets were fabriated from IM7/PETI-5 uni-directional tape with longitudinal tear straps, and the core is a titanium honeycomb core. The basic facesheet was a 12-ply laminate. The panel contained longitudinal tear straps spaced 10-in. apart that were 20-ply laminates. The panel also had transverse patch doublers at four locations. The facesheet of the the patch doublers was a 30-ply laminate. A 12-inch-long notch was machined through the longitudinal tear strap at the center of the panel to simulate discrete-source damage in the panel prior to testing. A detailed description of the test panel is presented in Ref. 54. A photograph of the panel is shown in Fig. 22.

The panel was initially loaded to $7.2 \mathrm{psi}$ internal pressure followed by axial and shear loading. The damage initiated at the tip of the notch and propagated at a $40^{\circ}$ path toward the adjacent tear straps. The damage progressed beyond the doublers at an applied of $7.2 \mathrm{psi}$ internal pressure, 3,900 lb/in. axial load, and $888 \mathrm{lb} /$ in. shear load. A photograph of the failed panel is shown in Fig. 23.

\section{Concluding Remarks}

NASA Langley Research Center and its industry partners advanced the understanding of the behavior of composite structures through large focused programs in the 1990s. The building-block approach to research in structural mechanics was vital to the success of the composite technology development programs. Examples that highlight the development of unique testing capabilities to support the building blocks include the Advanced Composites Technology Program, which began in 1989 and ended in 2000, and the High Speed Research Program, which began in 1994 and ended in 1999. Building block elements involving analysis and experimentation including coupons, stiffened and unstiffened panels, subcomponents, design detail articles and large full-scale components supported technology development. Verified tools and new approaches to composite design and fabrication and the development of new experimentation capabilities were critical parts of each program.

\section{References}

${ }^{1}$ Chen, V. L., Hawley, A. V., Klotzsche, M., Markus, A. M., and Palmer, R. J., “Composites Technology for Transport Primary Structure," First NASA Advanced Composites Technology Conference," NASA CP3104, Part 1, 1991, pp.71-126.

${ }^{2}$ Davis, J. G. Jr., "Overview of the ACT Program," Ninth DoD/NASA/FAA Conference on Fibrous Composites in Structural Design-Second NASA ACT Conference, NASA CP 3154, June 1992, pp. 3-25.

${ }^{3}$ Davis, J. G. Jr., "Overview of the ACT Program," Proceedings of the Ninth DoD/NASA/FAA Conference on Fibrous Composites in Structural Design, 1991, pp. 577-599.

${ }^{4}$ Davis, J. G. Jr., "Advanced Composites Technology Program," Third NASA Advanced Composites Technology Conference, NASA CP-3178, Part 1, 1993, pp. 49-78. 
${ }^{5}$ Markus, A., Thrash, P., and Grossheim, B., "Manufacturing Development and Requirements for Stitched/RTM Wing Structure," NASA CP 3229, 1993, pp. 503-523.

${ }^{6}$ Hawley, A., "Preliminary Design of a Transport Aircraft Composite Wing," Proceedings of the Fifth NASA/DoD Advanced Composites Technology Conference. NASA CP-3294, Volume 1, Part 2, pp. 717772.

${ }^{7}$ Hawley, A. V., "Development of Stitched/RTM Primary Structures for Transport Aircraft," NASA CR191441, 1993.

${ }^{8}$ Marcus, A., Thrash, P., and Rohwer, K., "Progress in Manufacturing Large Primary Aircraft Structures Using the Stitching/RTM Process," Third NASA Advanced Composites Technology Conference. NASA CP-3178, Part 1, 1993, pp. 453-479.

${ }^{9}$ Jegley, D. C. and Waters, W. A. Jr., "Test and Analysis of a Stitched RFI Graphite-Epoxy Panel with a Fuel Access Door.," NASA TM 108992, March, 1994.

${ }^{10}$ Sutton, J., Kropp, Y., Jegley, D., and Banister-Hendsbee, D., "Design, Analysis and Tests of Composite Primary Wing Structure Repairs," Presented at the 5th ACT Conference, Seattle, Washington, August 1994. NASA CP 3294, Vol. 1, Part 2, pp. 879-912.

${ }^{11}$ Hinrichs, S., Chen, V., Jegley, D., Dickinson, L., and Kedward, K., "Effect of Impact on Stitched/RFI Compression Panels," Presented at the 5th ACT Conference, Seattle, Washington, August 1994 NASA CP 3294, Vol. 1, Part 2, pp. 913-934.

${ }^{12}$ Hinrichs, S., Kropp, Y., and Jegley, D., "Manufacturing, Analysis And Tests Of Stitched/RFI Subcomponents," Presented at the 6th ACT Conference, Anaheim, CA, August 1995. NASA CP 3326 Volume 1, Part 1, pp. 209-231.

${ }^{13}$ Sutton, J., Kropp, Y., Jegley, D., and Banister-Hendsbee, D.: Design, Analysis and Tests of Composite Primary Wing Structure Repairs. Presented at the 5th ACT Conference, Seattle, Washington, August 1994. NASA CP 3294, Vol. 1, Part 2, pp 879-912.

${ }^{14}$ Jegley, Dawn, "Analysis of Selected Compression Splice Joint Locations in a Graphite-Epoxy Transport Wing Stub Box," NASA TM 110170, October 1995.

${ }^{15}$ Hinrichs, S. C., Kropp, Y., and Jegley, D. C., "Analysis and Testing of Stitched/RFI Subcomponents," Sixth NASA/DOD Advanced Composites Technology Conference. NASA CP-3326, Vol. 1, Part 1, 1996, pp. 209-233.

${ }^{16}$ Hinrichs, S., Jegley, D. C., and Wang, J. T., "Structural Analysis and Test of a Stitched Composite Wing Box," Sixth NASA/DOD Advanced Composites Technology Conference. NASA CP-3326, Vol. 1, Part 1, 1996, pp. 279-309.

${ }^{17}$ Hawley, A. V., "Detail Design Development of a Transport Aircraft Composite Wing," Sixth NASA/DOD Advanced Composites Technology Conference. NASA CP-3326, Vol. 1, Part 1, 1996, pp. 131-154.

${ }^{18}$ Drenth, S. E., and Renieri, M. P., "Cover Panel and Substructure Design for a Full-Scale Composite Transport Wing," $11^{\text {th }}$ DOD/NASA/FAA Conference on Fibrous Composites in Structural DesignSeventh NASA ACT Conference, Aug. 1996.

${ }^{19}$ Rohwer, K., Ghumman, A., and Markus, A., "Stitched/Resin Film Infusion (S/RFI) Manufacturing Technology Development," Proceedings of the $11^{\text {th }}$ DOD/NASA/FAA Conference on Fibrous Composites in Structural Design. Report number WL-TR-97-3009 pp. XIII-93-116.

${ }^{20}$ Wang, John T., Jegley, Dawn C, Bush, Harold G, and Hinrichs, Stephen C. "Correlation of Structural Analysis and Test Results for the McDonnell Douglas Stitched/RFI All-Composite Wing Stub Box." NASA TM 110267, July, 1996.

${ }^{21}$ Jegley, D. and Bush, H., "Test Documentation and Results of the Structural Test on the All-Composite Wing Stub Box." NASA TM 110204, April, 1997.

${ }^{22}$ Jegley, D. C., "Behavior of Compression-Loaded Panels with Stringer Terminations and Impact Damage.” Journal of Aircraft. Vol. 35, No. 12, pp.942-948, Nov.-Dec., 1998.

${ }^{23}$ Jegley, D. C., and Bush, H. G., "Structural Testing of a Stitched/Resin Film Infused Graphite-Epoxy Wing Box." NASA TM 210846, April, 2001.

${ }^{24}$ Karal, M, “AST Composite Wing Program - Executive Summary,” NASA CR 2001-210650.

${ }^{25}$ Jegley, D. C., Bush, H. G. and Lovejoy, A. E, "Evaluation of the Structural Response and Failure of a Full Scale Stitched Graphite-Epoxy Wing." Journal of Aircraft. Vol. 40, No. 6, pp. 880-886, NovemberDecember, 2003. 
${ }^{26}$ Dow, M. B. and Dexter, B. H., "Development of Stitched, Braided and Woven Composite Structures in the ACT Program and at Langley Research Center (1985-1997) Summary and Bibliography." NASA TP 97-206234, Nov. 1997.

${ }^{27}$ McGowan, D. M. and Ambur, D. R., "Structural Response of Composite Sandwich Panels Impacted With and Without Compression Loading". Journal of Aircraft, Vol. 36, No. 3, May-June 1999, pp. 596-602.

${ }^{28}$ Dávila, C. G., Ambur, D. R., and McGowan, D. M., Analytical Prediction of Damage Growth in Notched Composite Panels Loaded in Axial Compression. Journal of Aircraft, Vol. 37, No. 5, September-October 2000, pp. 898-905.

${ }^{29}$ McGowan, D. M., Ambur, D. R., Hanna, T. G., and McNeill, S. R., "Evaluation of the Compressive Response of Notched Composite Panels Using a Full-Field Displacement Measurement System". Journal of Aircraft, Vol. 38, No. 1, January-February 2001, pp. 122-129.

${ }^{30}$ McGowan, D. M., Young, R. D., Swanson, G. D., and Waters, W. A., "Compression Tests and Nonlinear Analyses of a Stringer- and Frame-Stiffened Graphite Epoxy Fuselage Crown Panel," Presented at the Fifth NASA/DoD/ARPA Advanced Composites Technology Conference, Seattle, WA, August 22-25, 1994.

${ }^{31}$ McGowan, D. M., and Ambur, D. R., "Compression Response of a Sandwich Fuselage Keel Panel With and Without Damage," Presented at the Sixth NASA/DoD/ARPA Advanced Composites Technology Conference, Anaheim, CA, August 7-11, 1995.

${ }^{32}$ Walker, T., Scholz, D., Flynn, B., Dopker, B., Bodine, J., Ilcewicz, L., Rouse, M., McGowan, D., and Poe, Jr., C., "Damage Tolerance of Composite Fuselage Structure," Presented at the Sixth NASA/DoD/ARPA Advanced Composites Technology Conference, Anaheim, CA, August 7-11, 1995.

${ }^{33}$ Murphy, D., Dopker, B., Ilcewicz, L., Biornstad, R., and McGowan, D., "Composite Structural Analyses Supporting Affordable Manufacturing and Maintenance," Presented at the Sixth NASA/DoD/ARPA Advanced Composites Technology Conference, Anaheim, CA, August 7-11, 1995.

${ }^{34}$ Walker, T. H., Minguet, P. J., Carbery, D. J.., Swanson, G. D., and Ilcewicz, L. B., "Advanced Technology Composite Fuselage - Structural Perfomrance," NASA CR-4732.

${ }^{35}$ Walker, T. H., Minguet, Ilcewicz, L. B.,Bodine, J.B., Murphy, D. P., Dost, E. F., "Benchmark Panels, " NASA CR-194969.

${ }^{36}$ McGowan, D. M., and Ambur, D. R., "Damage-Tolerance Characteristics of Composite Fuselage Sandwich Structures With Thick Facesheets," Presented at the 11th DoD/NASA/FAA Conference on Fibrous Composites in Structural Design, Fort Worth, TX, August 26-29, 1996.

${ }^{37}$ Ambur, D. R., McGowan, D. M., Baker, D. J., Hanna, T. G., and McNeill, S. R., "Compression Response of Notched Stiffened Composite Panels: Analyses and Experiments," Presented at the 1999 Society for Experimental Mechanics Conference on Theoretical, Experimental and Computational Mechanics, Cincinnati, OH, June 7 - 9, 1999.

${ }^{38}$ McGowan, D. M., Dávila, C. G., and Ambur, D. R., "Damage progression in Buckle-Resistant Notched Composite Plates Loaded in Uniaxial Compression." Presented at the 40th Structures, Structural Dynamics and Materials Conference, Seattle, WA, April 16-19, 2001. AIAA Paper No. 2001-1482.

${ }^{39}$ McGowan, D.M., "Skin/Stringer Large-Notch Compression Structural Tests and Analyses," Presented at the HSR Fuselage Structures Semi-Annual Review, St. Louis, MO, September 1998.

${ }^{40}$ McGowan, D.M., "Skin/Stringer Large-Notch Tension Structural Tests and Analyses," Presented at the HSR Fuselage Structures Semi-Annual Review, Los Angeles, CA, January 1998.

${ }^{41}$ McGowan, D.M., "Skin/Stringer Large-Notch Compression Structural Tests and Analyses," Presented at the HSR Fuselage Structures Semi-Annual Review, Los Angeles, CA, January 1998.

${ }^{42}$ McGowan, D. M., "PMC 3 Bay Panel and Crippling Tests \& Analyses," $2^{\text {nd }}$ Annual HSR Aircraft Materials and Structures Workshop, Hampton, VA, February 1996.

43،"High Speed Research Program Summary Report for Task 16 Materials and Structures Damage Tolerance and Task 25 Fuselage Structures," January 1995 to September 1999.

${ }^{44}$ ASTM Standard D 3410/D3410M-0 (1995), "Compressive Properties of Polymer Matrix Composite Materials with Unsupported Gage Section by Shear Loading," American Society for Testing and Materials, West Conshohocken, PA.

${ }^{45}$ ASTM Standard D 5379/D 5379M-98, "Test Method for Shear Properties of Composite Material by the V-notched Beam Method," American Society for Testing and Materials, West Conshohocken, PA.

${ }^{46}$ Williams, J.G., "The Multi-Span-Beam Shear Test Method For Studying Composite Transverse Shear Failure Characteristics," Presented at the $26^{\text {th }}$ AIAA/ASME/ASCE/AHS/ASC Structures, Structural Dynamics and Materials (SDM) Conference, Orlando, FL, April 1985. 
${ }^{47}$ Williams, J.G. and Rhodes, M. D., "Effect of Resin on Impact Damage Tolerance of Graphite/Epoxy Laminates. Composite Materials: Testing and Design (Sixth Conference)," ASTM STP 787, pp. 450$480,1982$.

${ }^{48}$ Jegley, D. C., "Compression Behavior of Graphite-Thermoplastic and Graphite-Epoxy Panels with Circular Holes or Impact Damage." NASA TP 3071, March 1991.

${ }^{49}$ Hilburger, M. and Starnes, J. H. Jr., "Parametric Study on the Response of Compression-Loaded Composite Shells with Geometric and Material Imperfections," NASA TM 2004-212676. Sept. 2004.

${ }^{50}$ Rankin, C. C., Brogan, F. A., Loden, W. A., and Cabiness, H. D., "STAGS User Manual, Version 3.0," Lockheed Martin Missiles \& Space Co., Inc., Rept. LMSC P032594, March 1999.

${ }^{51}$ Rouse, M., and Ambur, D. R., "Fuselage Response Simulation of Stiffened Panels Using a Pressure-Box Test Machine," AIAA-95-1362-CP, April 1995.

${ }^{52}$ Ilcewicz, L. B., Smith, P. J., and Horton, R. E., “Advanced Composite Fuselage Technology”. NASA CP 3178, 1992, pp. 97-156.

${ }^{53}$ Ambur, D. R., Cerro, J. A., and Dickson, J., "Analysis of a D-box Fixture for Testing Curved Stiffened Aircraft Fuselage Panels In Axial Compression and Internal Pressure," AIAA-94-1345-CP, April 1994.

${ }^{54}$ Mahler, M., Ley, R., Chandu, S., and Weichuan, L., "Propagation and Control of Crack-Like Damage In Curved Composite Panels Under Combined Loads," AIAA-2000-1534, April 2000. 